\title{
Finnish animal production research during the past 20 years
}

\author{
ESKO POUTIAINEN, MATTI NÄSI \& ASKO MÄKI-TANILA \\ Agricultural Research Centre of Finland \\ 31600 Jokioinen
}

\section{Introduction}

Animal production is a dominant feature of Finnish agriculture. Milk, meat and eggs constitute about three-fourths of total value added agricultural production. One-third of Finland's total arable land is allocated to hay, silage and pasture. Of a total productive area of 2.2 million hectares, around 1.0 million hectares are used for feed grain production. In central, eastern and northern Finland, only grasses and feed grain can be grown without great risks.

Finland's agricultural policy aims at a balanced, high-quality supply of food that meets domestic demand under all circumstances at a reasonable cost to consumers. During the two last decades the animal production has exceeded the limit of selfsufficiency and therefore has been subjected to regulative measures for reductions in production volume.

There is unanimous agreement that in the present situation, agricultural research should pay particular attention to facilitating the sector's adjustment to a reduction in overall production and try to find alternative production possibilities. Food quality and safety is considered another major subject of agricultural research, and aspects such as the utilization of biotechnology and environmental issues have more recently become important areas of study.

Owing to the central role of animal production in Finnish agriculture, inputs to research in this field have been rather high. During the last decades experimental facilities have been improved markedly. New buildings have been built and most of the old animal houses have been renovated so as to be suitable for modern animal experiments. At present, Finland has 750 individually fed cattle, 700 swine, 300 sheep, 12000 poultry and 350 horses for experimental purposes. The number of researchers and support personnel has increased only slightly within the same period thus restricting animal research. Animal production research is conducted mainly by the Agricultural Reseach Centre's institutes and experimental stations and at the various departments of the Faculty of Agriculture and Forestry of the University of Helsinki. 


\section{Dairy cattle feeding}

Nutrition research has aimed at improving the efficiency of feedstuff conversion into milk and meat for human consumption. Considerable research has been focused on the utilization of domestically produced feeds. The so-called "green line" feeding method, in which high-quality grass silage serves as the basal feed during the indoor season, was introduced to cattle feeding in the late 1960s.

Technical improvements in harvesting and safe methods of ensiling have essentially favored silage making. Flail harvestors that chopped and loaded grass and were equipped with an acid applicator, promoted the rapid increase of silage use in feeding. This model has been further developed, and has been successfully applied in practical cattle feeding since the 1970s.

A new method of grassland production was adapted simultaneous to the technical advancement made in silage making. Leys were based on grass species and nitrogen fertilization was employed to increase the yield and protein content of the grass.

The contribution of silage to the total feed intake of Finnish dairy cows has markedly and rapidly increased comprising ca. $25 \%$ of the total annual supply of feed units. The utility of silage as a feed depends both on the animals' voluntary intake as well as on its nutritional quality.

During the last 20 years of active research, most of the major practical aspects have been dealt with in a series of experiments. The following topics have been the most important:

Plant material: grass species, fertilization, stage of growth at harvest, method of harvesting

Additives: acid and acid mixtures, mixtures containing formaldehyde, bacterial and enzyme preparations and their mixtures

Storage losses: material and quality, prewilting

Feeding value: palatability, digestibility, energy and protein value, productive value in dairy cow and growing cattle feeding.
Numerous feeding experiments have been carried out on dairy cows and growing cattle especially. Experiments with cows have shown that by a silage supplemented with a small amount of hay, daily yields exceeding $14 \mathrm{~kg}$ may be obtained without loss of weight. Dietary supplementation with concentrates increases yields because the intake of digestible organic matter also increases.

Several feeding experiments have been conducted in order to study the level and type of concentrate supplementation. Comparisons of barley and oats have shown that on a weight basis oats have produced slightly more milk, but have lowered milk fat and protein content consistently in all experiments. Oats are also recommended for dairy cows instead of barley due to their better economy in milk production in addition to the resultant milk fat composition which is more desirable in human nutrition and dairy technology.

The optimal concentrate supplement for dairy cows has been investigated in many studies. The response to the replacement of barley with fibre-based concentrates has been variable depending on the fibre source. Supplements were fed equally on a DM basis and on a silage diet and the best response was obtained with unmolassed sugar beet pulp and barley fibre with solubles. The production response with fibrous concentrates was in all cases higher than that which could be expected from their lower energy values as evaluated by digestibilities.

A long term feeding study on dairy cows was performed with two home-grown forages supplemented with grain. The experiment comprised a silage and hay comparison in the three dairy breeds used in Finland: Ayrshire, Friesian and Finncattle and included two years of growth and six years of lactation. The differences in performance were slight among the forages, but a silage-cereal diet was found to be more profitable than a hay-urea-cereal diet.

An extensive study on strategies for concentrate feeding with ad lib. silage supply to high yielding dairy cows has been carried out both 
under experimental conditions and in practice. A simplified principle of a flat rate supplementation of concentrates was considered to be a realistic and economically feasible alternative provided the silage is of a high nutritional and palatable quality.

Several tests comparing the effects of different protein concentrates on milk yield with silage based rations have been carried out. Responses to protein supplements have been variable, although in most cases positive, depending to a large extent on the effects on digestibility and feed intake.

The protein requirement for milk production has been investigated intensively and various protein evaluation systems for ruminants have been developed. Protein protection treatments eg. for rapeseed meal have been tested in many experiments.

Basic research has emphasized the physiological and biochemical bases of feed intake, microbial degradation and digestion of feeds, absorption and utilization of nutrients.

\section{Growing cattle feeding}

In a series of feeding experiments on growing cattle, various forages and diet supplementation have been investigated. In some production trials re average daily weight gain of young bulls on sole silage feeding has ranged from 0.75 to $0.94 \mathrm{~kg} /$ day. Supplementation of the diet with up to $3.0 \mathrm{~kg}$ barley meal increased the rate of gain by about $230 \mathrm{~g}$. In the case of good silage, a similar response was achieved already by a $1.5 \mathrm{~kg}$ level of supplementation. Practically no further improvement has been found above a $3 \mathrm{~kg}$ supplementation level but the maximum response has been found to occur already at the level of $1.5-2.0 \mathrm{~kg}$.

When ordinary hay was compared with grass silage at two levels of barley supply, the estimated carcass gains of young bulls fed hay were 83 to $88 \%$ of that on silage. When different forages and supplementation levels were compared, it was concluded that carcass gains on hay rations were from 76 to $83 \%$ of those obtained on silage with the same level of concentrate supply. About $2 \mathrm{~kg}$ or more concentrate was needed on hay to reach the same carcass gain as that on silage.

The improvement of low digestibility forages by chemical and other processing methods has been investigated rather intensively. Sodium hydroxide treated straw has been used in many feeding trials involving growing cattle. Only moderate or rather poor performance has been obtained with diets based on treated straw. The need for an increased concentrate supplement has also become necessary in order to achieve reasonable growth rates.

\section{Non-ruminant feeding}

Investigations have sought to improve the efficiency of non-ruminant livestock production by expanding basic knowledge on nutritional and management practices that affect growth, production and reproduction. In the case of non-ruminants, research has focussed on finding the optimum levels for both domestic and imported protein feeds in order to attain high performance with pigs, poultry and furbearing animals.

\section{Pig feeding}

Feeding standards and methods have been investigated intensively in both breeding sows and growing pigs in order to achieve good performance and high carcass quality. A nutritional evaluation of domestic cereal grains and their protein supplementation has supplied good knowledge in pig nutrition, their requirements and feed utilization.

Domestic protein supplements such as rapeseed meal and pulses have proved reasonable replacements for soybean meal. Experiments in which fish meal has been used as the protein source have shown that only low levels can be used to avoid detrimental effects on meat quality. Promising results have been 
obtained in studies where natural protein sources have been balanced with the pure amino acids, lysine and methionine.

Some of the by-products of the milling and brewing industries, alcohol distillation, cheese making and abattoir have been evaluated in pigs as replacements for grain and some of these have been shown to be of high value while others are of low value. Various processing methods, hydrothermal and enzymatic treatments have been demonstrated to have potential in improving the feed value of some feedstuffs. In piglet feeds, processing and enzyme supplementation have increased the performance and health status of piglets.

The results have shown that even though it is possible to design nutritionally balanced diets based entirely on home-produced energy and protein feeds, this approach is not economical in the present situation. The supplementation of domestic feeds with restricted quantities of imported feeds has been found to be the most efficient and sound situation.

\section{Poultry feeding}

Nutrition research in poultry has been concentrated on the study of feed grains, the basic component of poultry feeds, and their supplementation. Such home-grown protein supplements as rapeseed meal and peas as well as protein rich agroindustrial by-products have been investigated intensively. Good production results can be obtained using domestic sources of protein, provided that the limiting amino acids are properly balanced with synthetic amino acids. A supplementation containing cellulolytic enzymes has improved layer performance when barley and oats have served as the basic grain sources.

Broiler nutrition research has been directed towards improving feed utilization when barley is used as a replacement for wheat in the diet. Barley contains non-starch polysaccharides which reduce nutrient absorption. Enzyme mixtures containing several cellulases and hemicellulases supplemented in barley based broiler diets have reduced digestive problems in the birds and increased feed conversion efficiency.

\section{Basic principles of breeding programs}

The genetic improvement of farm animals is based on simple principles. They involve normal out-breeding populations and fair comparisons of performance under common test conditions. The best animals are then selected and used for breeding the next generation. The expected genetic response is predicted from measuring to what extent the observed differences between individuals are inherited. In Finland, animal breeding research and development work is done in close cooperation between research and extension organisations, industry also provides some project funding.

A practical breeding program is constructed by assessing economic objectives, use of test resources, reliability of genetic evaluation method, and reproductive capacity in the species. Simultaneous contemplation of these features has produced coherent operational systems with the reproductive rate having the most important effect on the differences between species.

\section{From artificial insemination \\ to embryo transfer}

Finland has been amongst the most advanced countries in the utilization of artificial insemination (AI). In the 60's frozen semen replaced fresh semen in cattle and AI was succesfully set up in pigs so that now all the dairy cows and some $40 \%$ of sows are inseminated. Another significant development has been the rapid progress made in embryo technology since the first transfer in 1979. The advantages which superovulation and embryo transfer can offer have been studied through computer simulation. First steps have been taken also in molecular genetics research which aims for 
improvements in animal production technology.

\section{Dairy cattle breeding}

Research efforts have concentrated on the optimization of breeding programs under given economic objectives, test resources and desired accuracy of genetic evaluation. The main breed, Finnish Ayrshire, is a dualpurpose breed, where most of the selection on growth is by performance testing all AI bulls. Beef production requirements are also met by recommendations to inseminate the poorest cows with bulls of beef breeds. This and other on-farm breeding decisions can be based on the national cow evaluation system made available for farmers by on-line computer techniques. Health recording has been in operation since the early 80 's and can be expected to bring successful results because in Finland the number of daughters per bull is high enough even for poorly heritable traits such as disease resistance. During the last ten years, satisfactory genetic progress $(50-60 \mathrm{~kg}$ per year) has been made in milk yield. At the same time special programs have been set up to screen rare landrace breeds for maintaining the genetic variation for future needs.

\section{Pig breeding}

Pig breeding is based on centralized testing. Since the early 70's, all AI boars have been performance tested. The test provides sufficient accuracy for highly heritable traits and therefore accelerates progress in traits such as feed efficiency and backfat thickness. Meat quality has been given special attention in sib/progeny testing. Together with the systematic eradication of the halothane gene, various criteria for quality have been used and studied. Consequently, all AI boars and most of breeding herds are now halothane-free. Onfarm records on growth and reproduction have been utilized for within-farm selection and their use in national breeding programs has been investigated. A measure of the quality of Finnish pigs can be indicated by the substantial export of breeding material to several major pig production countries.

\section{Selection index}

Due to an efficient recording system, advanced measurement techniques and modern computing methods, genetic evaluation is done for several traits in many species. By considering the economic importance and genetic associations between traits as well as the information available, each test context is provided with a selection index where traits are evaluated appropriately. The indices were first set for pig breeding, but since 1983 also dairy bull selection has been based on an index.

\section{Genetic evaluation}

The most revolutionary development has taken place in genetic evaluation routines. Whereas the old methods could only very poorly take into account the environmental and genetic differences between animals over place and time, recently developed estimation routines can simultaneously remove effects due to feeding level, year and selection amongst parents. These so-called best linear unbiased predictions (BLUP) are obtained via the construction of mixed linear model equations. The first developments have occurred in dairy sire evaluation - BLUP has been used in Finland since 1981 - but now even more powerful methods have become feasible according to advancements in computing technology. Recent developments have made it possible to evaluate a larger number of animals under a uniform system and therefore also to monitor changes in genetic and environmental levels. 


\section{Other species}

Livestock production research also involves furbearing animals, horses, sheep, goats and reindeer. Feeding and management research has been carried out in all of the above animals. Being alternative production branches these would all have growth potential, and are therefore areas to be emphasized in future research.

Although the major breakthroughs in genetic improvement programs have been made in cattle and pigs, the same principles and methodology are applied in breeding programs for egg-laying hens, sheep and horses. Live animals or frozen embryos of Finnsheep have been exported to several countries with the aim of improving prolificacy in local sheep production. Fish farming and fur production are somewhat different from conventional farm production systems and therefore require special types of breeding programs.

\section{Conclusion}

Food research has been linked to agricultural research and this expands the scope of the animal production task to cover the whole production chain from the animal as a raw material to the processed finished product. Comprehensive research projects are needed in order to satisfactorily solve today's problems. The quality of animal products is of crucial significance today. In several research projects, objectives have been set for improvement in the composition of milk, meat and eggs according to consumer desires and to the recommendations of health specialists. Intensive research is in progress to meet this aim in the fields of animal breeding and nutrition. 